\title{
Letters
}

Website: bmj.com

Email: letters@bmj.com

\section{Integrated medicine}

Many orthopaedic surgeons do not think of patients just as malfunctioning elbows

EDITOR-As an orthopaedic surgeon specialising entirely in elbow and shoulder disorders I could not let the editor's choice on restoring the soul of medicine slip by without comment. ${ }^{1}$ Unlike the orthopaedic surgeon you refer to, I do read the $B M J$ each week (although I confess that my wife, a paediatrician, pays the subscription). I also note that in the editorial from the previous week on shoulder pain at work the one year prevalence of shoulder pain in the general population was estimated to be $20-50 \%$, but only $40-50 \%$ of those affected consult a primary care physician, let alone an orthopaedic surgeon. ${ }^{2}$

Most musculoskeletal complaints are influenced, if not caused, by circumstances of daily life. This is not just physical activity but psychosocial factors, including job pressures and stress at home. The commonest elbow complaint is tennis elbow. It is a considerable problem to those who have it; symptoms are undoubtedly influenced by a range of factors, and it is eminently suited to an integrated management approach. Those affected should consider changing the pattern of

\section{Advice to authors}

We prefer to receive all responses electronically, sent either directly to our website or to the editorial office as email or on a disk. Processing your letter will be delayed unless it arrives in an electronic form.

We are now posting all direct submissions to our website within 24 hours of receipt and our intention is to post all other electronic submissions there as well. All responses will be eligible for publication in the paper journal.

Responses should be under 400 words and relate to articles published in the preceding month. They should include $\leqslant 5$ references, in the Vancouver style, including one to the BMJ article to which they relate. We welcome illustrations.

Please supply each author's current appointment and full address, and a phone or fax number or email address for the corresponding author. We ask authors to declare any competing interest. Please send a stamped addressed envelope if you would like to know whether your letter has been accepted or rejected.

Letters will be edited and may be shortened.

bmj.com

letters@bmj.com their lives, reduce stress, and seek advice and help from complementary and conventional practitioners, and they may even benefit from seeing an orthopaedic surgeon. Orthopaedic surgeons should read the $B M J$, but equally the $B M J$ should be aware that many orthopaedic surgeons do not think of patients just as malfunctioning elbows.

Andy Carr professor of orthopaedic surgery Nuffield Orthopaedic Centre, Oxford OX3 7LD andy.j.carr@btinternet.com

1 Editor's choice. Restoring the soul of medicine. $B M$

2001;322 (7279). (20 January.)
Bongers PM. The cost of shoulder pain at work. BMJ 2001:322:64-5. (13 January.)

Integrated medicine means doctors will be in charge

EDITOR-Rees and Weil in their editorial on integrated medicine give a rather one sided view of the topic. ${ }^{1}$ They talk about selectively incorporating "elements" of complementary and alternative medicine into comprehensive treatment plans alongside orthodox methods of diagnosis and treatment. They also identify a need for doctors with the biomedical knowledge to be able to distinguish between the multiple options of complementary therapies. This comes across as orthodox biomedical cherry picking from the complementary field, to supplement conventional treatment. It also implies far greater knowledge and certainty about the relative merits of different complementary therapies than currently exists or will exist for some time to come.

It is precisely because of the limitations of biomedical knowledge and treatment that doctors (particularly general practitioners) began to open the door to complementary practitioners. During the late 1980s and early 1990s some general practitioners and complementary therapists developed pragmatic forms of collaboration, which represents "integration" on a more equal professional footing. In these arrangements, general practitioners often referred patients to complementary therapists for their opinion and advice, rather than with certainty that a particular treatment would help the patient. Also, they found that complementary therapists could make an important contribution to patient care, even in the absence of a clear cut orthodox medical diagnosis. The picture that emerged from these arrangements is very different from Rees and Weil's image of doctors in charge. When such interprofessional collaboration has been developing at the grass roots for so long and in an unsung way, why has the $B M J$ now dedicated an issue to integrated medicine? Surely not because the Royal College of Physicians is finally taking complementary medicine seriously. Nor because the Foundation for Integrated Medicine has been campaigning for its own medically dominant brand of integration.

The expansion of complementary therapies over recent decades has been widespread, consumer driven, and at the grass roots. We are now witnessing the establishment finally waking up to the potential threat from alternative healing practices if they continue to flourish unchecked. Despite the pious claim to be restoring the soul to medicine, what the $B M J$ theme issue really signifies is orthodox medicine's attempt to shore up its monopoly by bringing the professions working in complementary therapy under its wing.

David St George director

Centre for Integrative Sciences in Complementary and Alternative Therapies (CISCAT), London

NW3 2QU

david.stgeorge@ciscat.org.uk

1 Rees L, Weil A. Integrated medicine. BMJ 2001;322: 119-20. (20 January.)

\section{Finding the time is most important}

Editor-Dr Caleb Parry, an eminent 18th century physician of fashionable Bath Spa and one of the first doctors to describe thyrotoxicosis, once wrote that it is more important to know what sort of patient has the disease than what kind of disease the patient has. Unfortunately, the patient has rather slipped out of focus in the enthusiasm of modern orthodox medicine for technological solutions and scientific evidence. ${ }^{1}$ Patients with biological disease are frequently objectified as ill stomachs, sick lungs, or damaged kidneys, while the ever increasing multitude of people with functional illnesses that cannot be explained by a well defined pathology and cause often complain that doctors do not listen to them. It is the latter who make up such a large proportion of people seeking help from complementary medicine.

Therapists using complementary and alternative treatments do what doctors have so little time to do. They try to understand the sick person, and they use techniques that relax the emotional tension that often keeps the illness going. We all know from experience in childhood that getting better is not just a matter of taking the medicine: it requires time, rest, compassion, understanding, and care. Ill patients need to have faith 
in their carers and treatments if they are going to get well. Despite amazing achievements and dedicated practitioners, faith in orthodox medicine is at an all time low. An unsustainable caseload and cynical media that seem intent on undermining our institutions no doubt exacerbate this. Integrated medicine attempts to combine the best of both systems, but it is not just about adding a bit of acupuncture to the aspirin; it is about restoring an understanding of the patient, his or her attitudes, beliefs, personal history, and life situation to health care.

Research in integrated medicine should not just investigate the efficacy of a complementary set of instruments in the medical bag. We need to understand more clearly how the disharmony caused by life situations can make people ill through, for example, long term destabilisation of the autonomic nervous system and hypothalamopituitary-adrenal axis, and how relaxation, contemplation, confidence, and trust might work though neuroendocrine and neuroimmune mechanisms to facilitate self healing. The time is ripe for integrating the science and the humanity of health care around an understanding of the ill person. Let us hope we can find the time to seize the opportunity.

Nick Read professor

N.W.Read@sheffield.ac.uk

Jack Czauderna family doctor

Centre for Integrated Medicine, Institute of General Practice and Primary Care, Northern General Hospital, Sheffield S5 7AU

1 Rees L, Weil A. Integrated medicine. BMJ 2001;322 119-20. (20 January.)

\section{Science of the art of medicine does exist}

EDITOR-The perception is growing among those in the medical profession that a narrowly focused biological approach to patients is inadequate. There is a need to address the psychological aspects of patients' presentations and to provide appropriate interventions in these areas. This seems to be the argument offered for embracing complementary and alternative medicine, as presented by Rees and Weil in their editorial. ${ }^{1}$ There is another way.

There is a science of psychology and its practical application in clinical psychology and psychiatry. The problem is not that a science of the "art of medicine" does not exist, but that it has become divorced from general medical practice. Liaison psychiatrists and psychologists have been addressing these issues for many years. There is a substantial evidence base of randomised trials on which to base practice. ${ }^{2}$ Some have been published in the $B M J \cdot{ }^{3-5}$ It is amazing to me that liaison psychiatry or psychology was not mentioned in this special issue. Medicine can integrate psychological aspects of care without having to go alternative.

Michael Sharpe senior lecturer in psychological medicine

University of Edinburgh, Edinburgh EH10 5HF michael.sharpe@ed.ac.uk

1 Rees L, Weil A. Integrated medicine. BMJ 2001;322 119-20. (20 January.)
2 Royal Colleges of Physicians and Royal College of Psychiatrists. Joint working party report: the psychological car of medical patients; recognition of need and service provision London: Royal College of Physicians, 1995.

3 Thomas KB. General practice consultations: is there any point in being positive? BMJ 1987;294:1200-2.

4 Bredin M, Corner J, Krishnasamy M, Plant H, Bailey C, A'Hern R. Multicentre randomised controlled trial of nursing intervention for breathlessness in patients with lung cancer. $B M J$ 1999;318:901-4.

5 Speckens AE, Van Hemert AM, Spinhoven P, Hawton KE, Bolk JH, Rooijmans HG. Cognitive behavioural therap for medically unexplained physical symptoms: a rapt domised controlled trial. BMJ 1995:311:1328-32.

Adding complementary medicine will not stop descent into soulless medicine

EDITOR-Berman in his article expresses hope that an integrated approach to complementary and orthodox medical practice will help restore the soul to medicine. ${ }^{1}$ In nursing, the expansion of interest in complementary and alternative medicine began almost 20 years ago. The acceptance of it into mainstream care is, however, no guarantee that mainstream care will become any more holistic than it currently is. Doctors might well learn from a nursing experience on this occasion. It is just as possible for a practitioner of complementary and alternative medicine to get hooked on their particular health technology as an orthodox one.

The reductionist approach so prevalent in modern health care is not going to be resolved if all we mean by integration is colonising some bits of the field of complementary and alternative medicine that come up to our standards of scientific scrutiny. The technological intervention is only one aspect of the healing process, a conduit for some other, perhaps more significant, phenomenon to occur.

Hippocrates wrote that some people recover simply because of their satisfaction with the goodness of their doctor. He had a point. More and more evidence is pointing to the quality of the relationship between practitioner and patient as the key factor in diminishing the stress of dis-ease, taking the immunosuppressive brakes off and releasing people's inherent self healing capacity. Whether that comes from the healing "energies" that so many alternative approaches adopt or the neuropeptide flow observed in the leading work of Pert and others, probably does not matter. ${ }^{2}$ When doctors are able to "be with" patients as well as "do to" them with equal presence and skill, then we will indeed have (re)discovered the soul of medicine.

Such a holistic approach is of real benefit to patients. It will also help a lot of doctors. ${ }^{3}$ I give much of my time to a charity that provides rest and retreat facilities for nurses and doctors who are exhausted and burnt out. A core difficulty of many doctors who reach crisis point is the breakdown of relationships with their colleagues and patients; a loss of faith in their work through lack of ability and opportunity to work with real people and practise medicine as they know it should be done. Complementary and alternative medicine may help some doctors to get into right relationships and reconnect with their work and the people they seek to serve. Making it an add-on to the technological armoury of treatments will, however, do nothing to halt the downward spiral of soulless medicine.

Stephen G Wright professor

Faculty of Health, St Martin's College, Lancaster LA1 3JD

1 Berman BM. Complementary medicine and medical education. BMJ 2001;322:121-2. (20 January.)

2 Pert C. The molecules of emotion. New York: Scribner, 1997.

3 Wright SG, Sayre-Adams J. Sacred space-right relationship and spirituality in health care. Edinburgh: Churchill Livingand spirituality

\section{Medicine can't be everything to everyone}

EDITOR-With respect to the editorial by Berman, I do not understand why undergraduate education in "complementary" medicine is needed at all. ${ }^{1}$ Doctors simply need to do what is in their patients' best interest and they need to provide proved effective treatments. If patients do not want to follow a doctor's advice or want to submit to the advice of a charlatan or take some unsupervised medication, so be it. Patients must share some of the responsibility for their own decisions. Paternalism has long since been discredited as a way of medicine.

There are many ways to fulfil human needs that lie outside the range of medicine. In addition to physical and psychological wellbeing, we also seek things such as health and happiness, spiritual fulfilment, and a balance between labour and leisure. We seek them in many ways: by listening to music, praying, working, reading, meditating, hiking, or being with our friends and loved ones. These are all ways that we seek the good life without claiming that they are part of medicine. Neither do we feel obligated to prove their value. These are alternatives to medicine.

Why is this distinction important? Many proponents of alternative therapies do not claim that their therapies are alternatives to medicine, they claim that they are medicine, that they not only provide such things as spiritual fulfilment, balance, and happiness but also treat and cure specific diseases such as cancer, heart disease, and AIDS. What can we say about these claims? Had the statements been put in a medical publication, they would have been challenged on the basis of evidence. But when they are, proponents cry foul.

We are not talking about living the good life. We are talking about medicine. Medicine cannot fulfil every human need, yet with respect to whatever medicine does take responsibility for, it owes a scrupulous attention to empirical data to avoid misinforming and harming patients. Doctors do not need to spend large amounts of time learning about treatments that have never been shown to cure anything. Patients who do not want to follow a doctor's advice do not have to go to the doctor. Medicine can't be everything to everyone, and it should stop trying.

David Ramey veterinary surgeon

Private Veterinary Practice, Equine, PO Box 5231, Glendale, CA 91221, USA ponydoc@pacbell.net

1 Berman BM. Complementary medicine and medical education. BMJ 2001;322:121-2. (20 January.) 


\section{Cost of consultations is key issue}

EDITOR-The editorial by Rees and Weil on integrated medicine just misses the point. ${ }^{1}$ Is it not the case that patient satisfaction can be increased with a longer and more detailed consultation, with attention to lifestyle issues, and that perhaps improved satisfaction might be shown some day to improve objective outcomes, as suggested in your second editorial in the same issue? $?^{2}$ The NHS and other countries' regulated health systems drive down consultation time, for financial reasons. The longer consultation time that the private sector is able to give to those who can afford it might well be what patients in general would want and might even benefit from, but the cost of private specialist medical consultations, especially multiple consultations, will be beyond many pockets. The cost of consultations with holistic practitioners who are not medically qualified is much lower, and there is a sizeable group of people willing to pay for such a service.

Complementary and alternative medicine has by definition no scientific basis. Once any such treatment is accepted as proved it becomes part of mainstream medicine, irrespective of whether or not the NHS chooses to provide it. ${ }^{3}$

Michael J Goodman consultant physician Bury Health Care NHS Trust, Bury Genera Hospital, Bury BL9 6PG

1 Rees L, Weil A. Integrated medicine. BMJ 2001;322: 119-20. (20 January)

2 Reilly D. Enhancing human healing. BMJ 2001;322:120-1 (20 January)

Angell M, Kassirer JP. Alternative medicine-the risks of untested and unregulated remedies. $N$ Engl J Med 1998 $339: 839-41$.

\section{Road to betrayal is short}

EDITOR-Given the tide of political correctness, sackcloth and ashes, and plain kookiness that seems to have been engulfing the $B M J$ in recent years I am not surprised that integrated medicine was a recent theme issue. ${ }^{1}$ I am, however, appalled: if we join forces with alternative medicine we are not only betraying our scientific heritage but we are also a short step away from betraying our patients. It has taken hundreds of years to pull medicine away from the quagmire of superstition, witchcraft, mumbo-jumbo, and sheer quackery and turn it into something resembling a scientific pursuit. Now all of that progress seems to be in danger of being lost because we are too gutless to stand up to the criticism of scientific rationalism being offered to anyone who will listen.

I have had to rescue a man from the ministrations of his daughter, who informed me that she had changed his treatment to the homoeopathic equivalents of frusemide (furosemide) and an angiotensin converting enzyme inhibitor, with the result that he was admitted to hospital in severe heart failure. The likes of Jean Marie Charcot, Ignaz Semmelweiss, Robert Koch, and Thomas Lewis must be revolving at high speed in their last resting places if they can see what we are allowing to happen.
There is no necessary opposition between scientific medicine and humane, holistic, clinical practice, and the best clinicians throughout history have been skilled at combining both elements. To suggest that one cannot be a good scientis and a caring, compassionate doctor is nonsense. The laws of physics and chemistry are the same the world over, and because of a rigorous application of these laws and of the principles of the Enlightenment we now know that malaria is not caused by bad air or curses, that mental illness is not a sin, and that we can prevent outbreaks of typhoid by good public health measures and vaccination rather than by sacrificing goats at midnight.

Roger A Fisken consultant physician

Friarage Hospital, Northallerton, North Yorkshire DL6 1JG

RFisken@nahs-tr.northy.nhs.uk

1 Rees L, Weil A. Integrated medicine. BMJ 2001;322: 119-20. (20 January.)

\section{Practising integrated medicine}

Editor-I am a firm believer in integrated medicine. ${ }^{1}$ After each consultation I give my patients a teddy bear to cuddle and I play them a tune on the banjo.

Liam Farrell general practitioner

Crossmaglen, County Armagh BT35 9HD

1 Berman BM. Complementary medicine and medical education. BMJ 2001;822:121-2. (20 January)

\section{Water fluoridation}

\section{Meta-analysis of fluoridation and fractures has been done}

Editor-The article by McDonagh et al is valuable but not necessarily new in the area of fractures. ${ }^{1}$ They conclude that the evidence relating fluoridation to fractures is weak and shows no significant effect either way. This is identical to the conclusion that we published in a 1999 meta-analysis not cited by McDonagh et al but listed on Medline. ${ }^{2}$ This study located 26 studies in this area, compared with their 20, and reported a relative risk for fracture of 1.02 (95\% confidence interval 0.96 to 1.09 ). Interestingly, sex, urbanicity index, and the quality (but not duration) of the study explained $25 \%$ of the variation between studies in meta-regression.

Further work in this area will need to be done at an individual level to advance this field, but even this is problematic given the paper by Phipps et al in the same issue of the journal, which reports on a very large cohort of women. ${ }^{3}$ Nevertheless, it seems unlikely that water fluoridation to $1 \mathrm{ppm}$ has any significant effect on the incidence of fractures at a population level based on the current (albeit weak) evidence.

Graeme Jones senior research fellow Menzies Centre for Population Health research, GPO Box 252-23, Hobart, Tasmania, Australia G.Jones@utas.edu.au

Competing interests: None declared.
1 McDonagh MS, Whiting PF, Wilson PM, Sutton AJ, Chestnutt I, Cooper J, et al. Systematic review of water fluoridation. BMJ 2000;321:855-9. (7 October.)

2 Jones G, Riley M, Couper D, Dwyer T. Water fluoridation, bone mass and hip fracture: a quantitative overview of the literature. Aust N Z J Public Health 1999;23:34-40.

3 Phipps KR, Orwoll ES, Mason JD, Cauley JA. Community water fluoridation, bone mineral density, and fractures: prospective study of effects in older women. BMJ 2000; 321:860-4. (7 October.)

\section{Critical difference was overlooked}

EDITOR-I wish to comment on the paper by McDonagh et al on fluoridation and the study by Phipps et al on bone fracture. ${ }^{12}$ Although the paper by McDonagh et al deals a very serious blow to fluoridation on the basis of their findings of a much lower benefit for caries reduction than previously claimed and a much higher level of dental fluorosis than is acceptable, the authors do not make it clear that dental fluorosis is an indication of a toxic effect of fluoride, in a similar way that the blue line on gums is an indicator of lead poisoning. This raises the question of what other enzymes and proteins might be poisoned. The paper by McDonagh et al is only a partial scientific analysis. They did not consider work on the pineal or thyroid gland or many animal experiments showing an effect of fluoride on the brain.

On the basis of their meta-analysis, McDonagh et al claim that there is no evidence of a relation between hip fracture in elderly people and fluoridation but mischaracterise some of the key studies. For example, they indicated that $\mathrm{Li}$ et al showed no association. ${ }^{3} \mathrm{Li}$ et al showed, however, that at above $1.5 \mathrm{ppm}$ hip fracture rates were doubled and above $4 \mathrm{ppm}$ they were tripled. Although I pointed this out to McDonagh et al twice, they still report no association.

The most disturbing aspect of the study by Phipps et al is how much attention is given to the decrease in hip fracture incidence and how little to the increase in wrist fracture. The ostensible reason for this is that the $32 \%$ increase in wrist fracture is deemed insignificant. However, the supposed insignificance is based upon the fact that the $95 \%$ confidence interval is given as 1.00 to 1.71 . Had the interval been 1.01 to 1.71 , the increase would have been deemed significant. Bearing in mind that this result is achieved after many adjustments, the claim that long term exposure to fluoridated drinking water does not increase the risk of fracture is cavalier. It is also intriguing that McDonagh et al reported the study by Phipps et al about wrist fractures as significant with a confidence interval of 1.02 to 1.71 .

Overall, it is unfortunate that McDonagh et al have managed to convey the message that there is no evidence of harm from fluoridation, when in fact there is mixed evidence of harm-a critical difference.

Paul Connett professor of chemistry St Lawrence University, Canton, New York, NY 13617, USA

Competing interests: PC is a founding member of the Fluoride Action Network, an international coalition of citizens and scientists seeking an end to fluoridation worldwide. With his son he runs the web page www.fluoridealert.org. 
1 McDonagh MS, Whiting PF, Wilson PM, Sutton AJ, Chestnutt I, Cooper J, et al. Systematic review of water fluoridation. BMJ 2000;321:855-9. (7 October.)

2 Phipps KR, Orwoll ES, Mason JD, Cauley JA. Community water fluoridation, bone mineral density, and fractures: prospective study of effects in older women. $B M$ J 2000;321:860-4. (7 October.)

3 Li Y, Liang C, Siemenda C, Ji R, Sun S, Gao J, et al. Effect of long term exposure to fluoridation in drinking water on risks of bone fractures. 1999. (Unpublished report, submitted by author.)

\section{Clearer evidence of benefits and risks is needed}

EDITOR-The systematic review by McDonagh et al indicates that the benefits and risks of water fluoridation balance each other in that a median of six people would need to receive fluoridated water for one to benefit while six people would have to be exposed to it for one additional person to develop dental fluorosis. ${ }^{1}$ It also shows that in artificially fluoridated areas on average 48\% of the population has this condition. Since dental fluorosis, whether of aesthetic concern or not, is the first visible sign of poisoning by fluoride, which is as toxic as arsenic and lead, this shows that about half the population in these areas is suffering from some degree of harm. This suggests that water fluoridation is an unacceptable method of reducing dental decay.

The benefits may be overestimated whereas the risks may be grossly underestimated. A confounding factor that was repeatedly pointed out to the review panel but not taken into account is that fluoride delays tooth eruption. In comparing children of similar age, this biases the results in favour of fluoride. ${ }^{2}$

The review by McDonagh et al does point out the possibility of adverse effects of fluoride on the thyroid gland. Fluorine displaces iodine from its compounds and may be at least one of the factors, if not the major one, in causing the delay in tooth eruption. It may also be a factor in the increased neonatal death rate described by Schatz in a fluoridated area of Chile, ${ }^{3}$ a paper that was submitted to the review but does not seem to have been commented on. Birmingham and the West Midlands, fluoridated since the early 1960s, have one of the highest neonatal death rates in Britain, ${ }^{4}$ and an exceptionally high rate of diabetes. ${ }^{5}$

Since the established view is that water fluoridation is perfectly safe, little research into possible adverse effects has been carried out on human populations drinking artificially fluoridated water, and correlations are not made between increasing prevalences of illness and water fluoridation. There is, however, a large body of experimental and animal evidence, studies that fell outside the remit of the review by McDonagh et al, which attest to the toxic effects of fluoride on the stomach, kidneys, pancreas, thyroid, brain and immune system, as well as on bones and teeth. Since animal studies are the gold standard of drug safety testing, this evidence should also be considered before mass medicating any further sections of the community. If the York review shows anything, it is that there should be a moratorium on all current fluoridation schemes until clearer evidence of benefits and risks becomes available.

Sheila L M Gibson hospital practitioner

Robin G Gibson consultant physician

Glasgow Homeopathic Hospital, Glasgow G120XQ

Competing interests: SLMG is medical adviser to the National Pure Water Association and member of an advisory panel to the systematic review of water fluoridation. RGG-none declared.

1 McDonagh MS, Whiting PF, Wilson PM, Sutton AJ, Chestnutt I, Cooper J, et al. Systematic review of water fluoridanutt I, Cooper J, et al. Systematic review ot

2 Gibson SLM, Gibson RG. Water fluoridation and tooth decay in 5 year olds. BMJ 1998;316:231.

decay in 5 year olds. BMJ 1998;316:231. 3 Schatz, A. Increased death rates in Chile associated with
artificial fluoridation of drinking water, with implication artificial fluoridation of drinking water, with implication iies 1976;2:1-17.

4 Settatree R, Wyldes M, Tonks A. Stillbirth and neomatal deat 1991-1994. Report of national, regional, district and unit mortality rates. Solihull: West Midlands Perinatal Audit, 1996.

5 Regional Director of Public Health. Partners in health Birmingham: West Midlands Regional Health Authority, 1992:2 1-35. (Public health report.)

\section{Government should meet commitment} made in white paper

EDITOR-The systematic review by McDonagh et al confirmed that fluoridation of the water supplies is effective in reducing dental caries and has no detrimental effects on public health. ${ }^{1}$ It is now time for the government to meet its commitment made in the white paper Saving Lives: Our Healthier Nation, published in July 2000, to require water companies to fluoridate where there is strong local support for doing so.

The method used, however, limits the information that should be considered by health and local authorities when deciding whether or not to implement this important pubic health measure. The stringent criteria used to measure effectiveness failed to evaluate the full benefits. The benefits of fluoridation are cumulative over a lifetime for those who consume fluoridated water over that period. ${ }^{2}$ To ignore the evidence of value to the adult population underestimates the true impact of the public health measure.

The only adverse effect that the review discovered was that of cosmetically unacceptable fluorosis. The estimates of the prevalences of cosmetically unacceptable fluorosis, while based on the international literature, appear too high for the situation in the United Kingdom. For example, the estimate of $10 \%$ of the population in fluoridated communities suffering from cosmetically unacceptable fluorosis runs against best current evidence for this country, which suggests that this affects only $3 \%{ }^{3}$

Those who will be called on to make decisions on this very important matter deserve to have the full picture, particularly as it is relevant to this country, on which to decide.

P J Holloway emeritus professor

Turner Dental School, University of Manchester, Manchester M15 1FH

Competing interests: None declared.

1 McDonagh MS, Whiting PF, Wilson PM, Sutton AJ, Chestnutt I, Cooper J, et al Systematic review of water fluoridation. BMJ 2000;321:855-9. (7 October.)
2 Thomas FD, Kassab JY. Fluoridation in Anglesey: a clinical study of dental caries in mothers at term. Brit Dent J 1992;181:36-140.

3 Tabari ED, Ellwood R, Rugg-Gunn AJ, Evans DJ, Davies RM. Dental fluorosis in permanent incisor teeth in relation to water fluoridation, social deprivation and toothpaste use in infancy. Brit Dent J 2000;189:216-20.

\section{Authors' reply}

EDITOR-Our study was a review of primary studies; hence the meta-analysis by Jones et al was not cited. We were aware of their work, however, and did screen the six studies included in their analysis and not in ours. We excluded these studies because they did not meet our inclusion criteria. Both Connett and Gibson comment on our lack of describing fluorosis as an indication of a toxic effect of fluoride. In fact in our analysis, fluorosis is considered an individual negative outcome, as is, for example, bone fracture or cancer. Regarding Connett's comment about the lack of consideration of thyroid and pineal studies, we emphasise that any study meeting inclusion criteria was included (as were two thyroid studies). Animal studies were excluded because they provide less reliable estimates of effect and where human data are available we think these should not bear significant weight on decisions about interventions. Connett also indicates that we have misrepresented a study by $\mathrm{Li}$ et al. ${ }^{1}$ Our analysis of bone fracture relates to water fluoridation levels close to $1 \mathrm{ppm}$ (the relevant concentration for artificial fluoridation). At $1 \mathrm{ppm}$, the risk of fracture found by Li et al was not increased.

We agree with Holloway that the effect of fluoridation should be examined over time, which is one reason we excluded cross sectional studies of positive effects. We did not exclude studies of adults, but only one met the inclusion criteria. Holloway further states that our estimates of fluorosis seem too high for the United Kingdom. The advantage of a systematic review is to bring together as much evidence as possible to get a clearer picture of the true effect. Rather than depend on a single study, we have more confidence in the pooled studies. In the meta-regression analysis, geographical location was not found to be significantly associated with fluorosis; neither were other geographically specific variables such as temperature and altitude.

Gibson, one of our advisory panel members, comments that delayed eruption of teeth potentially caused by fluoridation was ignored. This issue was not ignored in our review, but we found only one study that met inclusion criteria. This is an area that may merit further research. Counter to what Gibson writes, the Schatz study of neonatal death was indeed included in our review, and was commented on in our full report. ${ }^{2}$ Our review of water fluoridation is specific and appropriately narrow in focus. It is not the answer to the question of whether or not to fluoridate. Our review found a benefit in the form of reduction in caries, balanced against a dose related increase in fluorosis. We said that no clear evidence of other potential negative effects was found. We have been assiduous in our paper, our full 
report, and our contacts with the media, not to convey a message of no evidence of harm. We suggest caution against overinterpretation of our results and emphasise again that the quality of these data on benefit and harm is only low to moderate.

Marian S McDonagh research fellow NHS Centre for Reviews and Dissemination

Jos Kleijnen professor

NHS Centre for Reviews and

Dissemination,University of York, York YO10 5BB

Competing interests: None declared.

1 Li Y, Liang C, Siemenda C, Ji R, Sun S, Gao J, et al. Effect of long term exposure to fluoridation in drinking water on risks of bone fr

2 NHS Centre for Reviews and Dissemination. A systematic review of public water fluoridation. York: University of York, review of public water

\section{Results should be viewed with concern} rather than applause

EDITOR-Phipps et al state that a 95\% confidence interval on relative risk for wrist fracture of 1.00-1.71 due to community water fluoridation is not significant and surmise that it may be one of the most cost effective methods for reducing the incidence of fractures related to osteoporosis, on the basis of reduced spine and hip fracture after adjustment for a dozen factors in addition to age. ${ }^{1}$ These are specific to bone mass density, and the changes in bone mass density in table 3 (due to and correlated with fluoride exposure) are congruent with changes associated with fluoride treatment. ${ }^{2-4}$ In the 1994 guidelines of the Food and Drugs Administration (published in 1997) for preclinical and clinical evaluation of agents used in preventing or treating postmenopausal osteoporosis, the relation between increased bone mass density and reduced fracture risk has been validated for patients receiving oestrogens, but not fluoride. It is now recommended that clinical trials be restricted to the axial skeleton only, provided that the patient has good peripheral bone density, renal function, and vitamin D status, factors not considered in the multivariate analysis of Phipps et al. Thus, the analysis is not entirely cogent regarding fracture. Rather, the two most significant trends for age adjusted only with continuous exposure in figure 5 are again increased wrist fracture $(\mathrm{P}=0.012)$ and maybe some decrease in spine fracture $(\mathrm{P}=0.079)$.

The benefit (if any) to the vertebra from increased bone mass is now recognised to be at the expense of increased risk of fracture to the parts of the skeleton that are subject to forces other than compressive loading. The new bone formed is weak and structurally abnormal because of fluoride's alteration of the normal remodelling process (FDA Consumer, April 1991), and this decrease in quality and strength presents both clinically and experimentally (with and without calcium supplementation). This osteogenic effect occurs at plasma fluoride concentrations associated with fluoridated areas, with total accumulation being directly proportional to total lifetime ingestion (unless exacerbated by the onset of chronic renal insufficiency). The net dosage increment associated with the age and weight adjusted increase in five year relative fracture risk comparing $1 \mathrm{mg} / \mathrm{l}$ with 4 $\mathrm{mg} / \mathrm{l}$ fluoride in drinking water is commensurate with 20 years of community water fluoridation and clinical experience has taught that denser bones are not necessarily better bones. ${ }^{45}$ Thus the 20 year changes in bone mass density reported by Phipps et al should be viewed with some concern rather than applause.

T C Schmidt director

Clairemont Town Council, San Diego, CA

92117-4038, USA

thomas.c.schmidt@lmco.com

Competing interests: None declared. TCS agrees with Douglas Carnall (BMJ2000;321:904) that those who wish to take fluoride should get it from toothpaste rather than the water supply.

1 Phipps KR, Orwoll ES, Mason JD, Cauley JA. Community water fluoridation, bone mineral density, and fracture prospective study of effects in older women. $B M$ 2000;321:860-4. (7 October.)

2 Bauer DC, Browner WS, Cauley JA, Orwoll ES, Scott JC, Black DM, et al. Factors associated with appendicular bone mass in older women. The Study of Osteoporotic Fracture Research Group. Ann Intern Med 1993;118:657-65.

Riggs BL, Hodgson SF, O'Fallon WM, Chao EY, Wahner HW, Muhs JM, et al. Effect of fluoride treatment on the fracture rate in postmenopausal women with osteoporosis. N Enol J Med 1990:320.802-9.

4 Dequeker J. Declerck K Fluor(ide) in the treatment of Defreatment of osteoporosis. An overview of thirty years clinical research.
Schweiz Med Wochenschr 1993;123:2228-34.

5 Sowers MF, Clark MK, Jannausch ML, Wallace RB. A prospective study of bone mineral content and fracture in communities with different fluoride exposure. Am J Epidemiol 1991;133:649-60.

\section{Authors' reply}

EDITOR-Connett voiced his concern about our interpretation of fracture risk associated with long term exposure to community water fluoridation. After adjusting for known confounders, we found a slight, yet significant reduction in the risk of fracture of the hip and spine and a trend towards an increased risk of fracture of the wrist. Following standard statistical convention, we reported that the increase in the risk of wrist fracture was not significant because the $95 \%$ confidence interval included 1.0.

The decrease in the risk of fractures in both spine and hip outweighs the trend towards increased wrist fracture. Fractures of the hip account for the major burden of osteoporosis and can result in admission to nursing homes and death. Wrist fractures, however, tend to occur in healthy more active women and do not have the economic or social burden associated with hip fractures. ${ }^{1}$ Our conclusion that long term exposure to fluoridated drinking water does not increase the risk of fracture is also based on the fact that we saw no association when we evaluated all non-vertebral fractures (odds ratio $0.96,95 \%$ confidence interval 0.83 to 1.10). Connett also refers to the fact that the fluoridation review of the University of York quotes our confidence interval for wrist fractures as 1.02 to 1.71 . For their review, the York team used our draft results that were not fully adjusted for the known risk factors for fracture.

Schmidt focuses on the changes we found in bone mineral density and the association between bone mass density and fracture risk. He says that denser bones are not necessarily better bones. We disagree with this statement and cite the alendronate and raloxifene clinical trials as prime examples. These trials found that individuals taking raloxifene and alendronate had increased spinal bone mass density along with a decrease in vertebral fracture risk. ${ }^{2 .}$ In addition, trials testing time released or low dose fluoride for the treatment of osteoporosis also found both increased spinal bone mass density and fewer vertebral fractures. ${ }^{45}$ On the basis of the increasing literature documenting a significant correlation between increased bone mass density and reduced fracture risk, we stand by our claim that community water fluoridation does not increase the risk of osteoporotic fractures in older women and may actually slightly reduce the risk of hip and vertebral fractures.

\section{Kathy Phipps associate professor \\ Eric Orwoll professor of medicine \\ Jill Mason associate professor \\ Oregon Health Sciences University, Portland,} OR 97201, USA

Jane Cauley associate professor of epidemiology University of Pittsburgh, Pittsburgh, PA 15261, USA Competing interests: None declared.

1 Kelsey JL, Browner WS, Seeley DG, Nevit MC, Cun SR. Risk factors for fractures of the distal forearm and proximal humerus. The Study of Osteoporotic Fractures Research Group. Am J Epidemiol 1992;135:477-89.

2 Hochberg MC, Ross PD, Black D, Cummings SR, Genan HK, Nevitt MC, et al. Larger increases in bone mineral density during alendronate therapy are associated with a lower risk of new vertebral fractures in women with postmenopausal osteoporosis. Fracture Intervention Trial Research Group. Arthritis Rheum 1999;42:1246-54.

3 Ettinger B, Black DM, Mitlak BH, Knickerbocker RK, Nickelsen T, Genant HK, et al. Reduction of vertebral fracture risk in postmenopausal women with osteoporosis treated with raloxifene: results from a 3-year rapomized clinical wial. Multiple Outcomes of Randomized clinical trial. Multiple Outcomes of Raloxifene Evaluation

4 Reginster JY, Meumans L, Zegels B, Rovati LC, Minne HW, Giacovelli G, et al. The effect of sodium monofluorophosphate plus calcium on vertebral fracture rate in postmenopausal women with moderate osteoporosis. A randomized, controlled trial. Ann Intern Med 1998;129:1-8.

5 Pak CY, Adams-Huet B, Sakhaee K, Bell NH, Licata A, Johnston C, et al. Comparison of nonrandomized trials with slow-release sodium fluoride with a randomized placebo-controlled trial in postmenopausal osteoporosis. J Bone Miner Res 1996;11:160-8.

\section{Little is known about the safety of} fluoridation

EDITOR-Your comments in "This week in the $B M{ }^{\prime}$ ' and the editorial by Hausen treated the study by Phipps et al on community water fluoridation, bone mineral density, and fractures, which you published alongside the systematic review of water fluoridation by McDonagh et al, as introducing new evidence that should alleviate remaining concerns about the safety of fluoridation..$^{1-3}$ The paper by Phipps et al, which seemed to show a slightly lower risk of fractures, had been fully accounted for in the systematic review by McDonagh et al, where it achieved the lowest rating (high risk of bias), in common with all but one of the studies on bone problems in the world literature. It is therefore premature to suggest that we know all the answers about fluoride and bones, let alone about the safety of fluoridation overall.

Baldwin of Bewdley

House of Lords, London SW1A OPW

edward@baldwin.dircon.co.uk 
Competing interests: None declared. BB holds the honorary position of vice president of the National Pure Water Association

1 Hausen HW. Fluoridation, fractures, and teeth. $B M$ J 2000;321:844-5. (7 October.)

2 Phipps KR, Orwoll ES, Mason JD, Cauley JA. Community water fluoridation, bone mineral density, and fractures: prospective study of effects in older women. BMJ 2000;321:860-4. (7 October.)

3 McDonagh MS, Whiting PF, Wilson PM, Sutton AJ, Chestnutt I, Cooper J, et al. Systematic review of water fluoridation. BMJ 2000;321:855-9. (7 October.)

\section{Ireland has less decay in non-fluoridated} communities

EDITOR-I share Carnall's views on fluoridation. ${ }^{1}$ The Republic of Ireland has $73 \%$ water fluoridation. So what is its dental experience? In the most recent figures published by the World Health Organization for tooth decay in Ireland, the country lies in only sixth place for tooth quality. ${ }^{2}$ Of the five countries with better teeth, four do not fluoridate and the United Kingdom has only 10\% fluoridation. In Ireland there are more decay free teeth in non-fluoridated communities.

Fifty per cent of our population has dental fluorosis. I see patients daily in my surgery who are damaged by fluoride. They do not smile, they are teased at school, and they are traumatised by having "rotten" teeth. Is it an acceptable cost-benefit payoff to cause a dental disease in half of the population to reduce tooth decay by a supposed $15 \%$ ? The idea of mass medicating an entire population is inherently flawed. When I prescribe drugs I do so with the knowledge of the patient's age, weight, and medical history. Water fluoridation is prescribed by thirst. The more you drink the more you get. Is this science?

Don Mac Auley dental surgeon

Navan, County Meath, Republic of Ireland dentist@esatclearie

1 Carnall D. Website of the week: Water fluoridation. $B M J$ 2000:321:904. (7 October)

2 Marthaler T.M. The prevalence of dental caries in Europe 1990-1995. Caries Res 1996;30:237-55.

3 WHO Oral Health Country/Area Profile Programme Ireland. Oral disease prevalence. Available at: www. whocollab.od.mah.se/euro/ireland/data/irelandcar.html; accessed 6 June 2001

\section{Pregnancy is contraindication for rubella vaccination still}

EDITOR-Some of the statements in Josefson's news report of the Canadian study on inadvertent rubella vaccination in pregnancy might mislead a British audience. ${ }^{1}$ Since 1990 the Department of Health for the United Kingdom has advised that conception should be avoided for one month, rather than three months, after rubella vaccination. Furthermore, termination of pregnancy is no longer recommended even if vaccination does occur shortly before conception or during pregnancy. ${ }^{2}$ This was in the light of data collected in the United States, Germany, Sweden, and the United Kingdom, in which the outcome of pregnancies affected by inadvertent rubella vaccination was monitored.

In England and Wales fewer than 40 terminations associated with rubella vaccina- tion have been reported over the past 10 years, compared with over 400 in the previous 10 years. ${ }^{4}$ Over 100 live born infants have been reported to the rubella vaccination in pregnancy study, which is part of the national congenital rubella surveillance programme; $60 \%$ of their mothers were known to be susceptible to rubella at vaccination. No infant has been reported with congenital rubella syndrome. Nevertheless, among 25 tested infants whose susceptible mothers were vaccinated more than one week after conception, four had rubella immunoglobulin $\mathrm{M}$ at birth. Although it is reassuring that no child has been born with symptoms attributable to congenital rubella infection, it is quite another matter-and not appropriate-to suggest that rubella vaccine is safe in early pregnancy.

Pat Tookey senior research fellow

National Congenital Rubella Surveillance Programme, Institute of Child Health, London WC1N 1EH

p.tookey@ich.ucl.ac.uk

1 Josefson D. Rubella vaccine may be safe in early pregnancy. BMJ 2000-322:695. (24 March)

Department of Health. Immunisation against infections disease. London: Stationery Office, 1996

3 Tookey PA, Jones G, Miller BHR, Peckham CS. Rubell vaccination in pregnancy. Commun Dis Rep CDR Wkly 1991;1:R86-8.

4 Office for National Statistics. Abortion statistics. London Stationery Office, 2000

\section{Maternal age and risk of type 1 diabetes in children}

\section{Flawed analysis invalidates conclusions}

EDITOR-The conclusion drawn by Bingley et al, of dependence on both birth order and maternal age, is a tempting explanation of previous ambiguous results. ${ }^{1}$ I believe, however, that their study is seriously flawed in the analysis of data, to an extent that the results are completely meaningless.

There are three apparent problems.

Firstly, the cohort studied consists of children with a sibling diagnosed with type 1 diabetes. Hence every only child in the study must be a case. Roughly half of the children from two child families will be cases, and so on. This immediately produces an (inverse) association between the number of siblings and the diagnosis of type 1 diabetes. To see this clearly, suppose that cases occur purely at random. To make the numbers easy, suppose the incidence is $1 \%$. Now select 1000 only child cases and 1000 cases with a single sibling. Almost half of the 2010 expected cases will be only children, but none of the non-cases.

Moreover, birth order relates to family size: an only child cannot be a second born. So of our hypothetical 3000 children with 2010 cases, 1505 cases will be expected to be first born, compared with only 495 of 990 non-cases; a risk-ratio of 1.5 . The dependence on maternal age then follows immediately if we allow that women who have their first child later tend to have fewer children. The results Bingley et al obtain are therefore consistent with the null hypothesis of no association between maternal age or birth order with type 1 diabetes.

Secondly, Cox regression is essentially a form of nested case-control study and relies on the assumption that the events are independent. This does not seem a reasonable assumption when the study contains many sets of siblings, so the confidence intervals calculated are probably too small.

Thirdly, it is not clear how the result would generalise to a population of women who have not had a diabetic child. The first of the above points is at first sight the most serious, although reanalysis could overcome it: only children should be excluded and a single control selected from each family to eliminate the family size effect. It is hard to see, however, how you would ever circumvent the third argument.

Graham Byrnes biostatistician

Clinical Epidemiology and Health Service Evaluation Unit, Royal Melbourne Hospital, Parkville, Victoria 3050, Australia

Graham.Byrnes@mh.org.au

1 Bingley PJ, Douek IF, Rogers CA, Gale EAM. Influence of maternal age at delivery and birth order on risk of type 1 diabetes in childhood: prospective population based family study. BMJ 2000;321:420-4. (12 August.)

Relative risks by maternal age are biased

EDITOR-Statisticians familiar with survival analysis techniques may have spotted methodological problems in the paper by Bingley et al, ${ }^{1}$ but other readers might have been suspicious about the very high risks of diabetes among the offspring of families in the study depicted in figure 1, especially in the oldest maternal age groups, where fewer than $40 \%$ of offspring would be predicted to be free of diabetes by 20 years of age.

Bingley et al ascertained families through affected children (probands) and then applied survival analysis techniques to all the offspring in these families, including probands, with age at diagnosis of affected children as the end point and follow up in unaffected children censored at their age on the date of last contact. This strategy will result in ascertainment bias, which will lead to overestimation of the risk of diabetes in these families. The mothers in this study will grow older, and some will have more children, most of whom will not develop diabetes. These children, together with ageing younger children in the family, will contribute to improving the rates of diabetes free survival in the analysis depicted in figure 1 , particularly in the oldest maternal age categories. By ignoring these children Bingley et al introduce biases into the relative risks for maternal age categories shown in their table. Their plot of estimated risks in figure 3 obtained by extrapolating these relative risks to birth cohorts in England and Wales is also flawed.

We conducted a large case-control study including over 1000 cases of childhood type 1 diabetes and over 2000 controls drawn from eight European centres in which we collected data on the family history of type 1 diabetes in the siblings of both cases and controls. ${ }^{2}$ To explore the possible extent of these biases, we reanalysed the data from the 
Comparison of association between maternal age and type I childhood diabetes using strategy of Bingley et al ${ }^{1}$ and Mantel-Haenszel odds ratio in EURODIAB study²

\begin{tabular}{lcc}
$\begin{array}{l}\text { Maternal age } \\
\text { (years) }\end{array}$ & $\begin{array}{c}\text { Relative hazard } \\
(\mathbf{9 5 \%} \mathbf{~ C l})^{*}\end{array}$ & $\begin{array}{c}\text { Odds ratio } \\
\mathbf{( 9 5 \% ~} \mathbf{~ I ) ~}\end{array}$ \\
\hline$<20$ & 1.00 & 1.00 \\
\hline $20-24$ & $1.45(1.07$ to 1.96$)$ & $1.03(0.75$ to 1.42$)$ \\
\hline $25-29$ & $1.89(1.40$ to 2.54$)$ & $1.30(0.94$ to 1.79$)$ \\
\hline $30-34$ & $2.32(1.70$ to 3.16$)$ & $1.39(0.99$ to 1.96$)$ \\
\hline$\geqslant 35$ & $2.88(2.05$ to 4.05$)$ & $1.42(0.95$ to 2.14$)$ \\
\hline
\end{tabular}

* Strategy of Bingley et al.

cases and their siblings using the same strategy as Bingley et al, with follow up ending at the time of our contact with the families. The table shows that the results are similar to those of Bingley et al.

When, however, we analysed our data using appropriate statistical methods comparing the distribution of maternal age in cases with the corresponding distribution in controls with the Mantel-Haenszel odds ratio pooled over our eight centres, we found a much weaker relation with maternal age (table). These results are more in keeping with published data and were little altered by adjustment for potential confounding variables.

C C Patterson senior lecturer in medical statistics Department of Epidemiology and Public Health, Queen's University Belfast, Belfast BT12 6B] c.patterson@qub.ac.uk

G Dahlquist professor of paediatrics Department of Clinical Science, Umeå University, S-90185 Umeå, Sweden

G Soltész professor of paediatrics

Department of Paediatrics, Pécs University, H-7623 Pécs, József A. u. 7, Hungary

On behalf of the EURODIAB Substudy 2 Study Group.

1 Bingley PJ, Douek IF, Rogers CA, Gale EAM. Influence of maternal age at delivery and birth order on risk of type 1 maternal age at delivery and birth order on risk of type 1 ily study. $B M J$ 2000;321:420-4. (12 August.)

2 Dahlquist GG, Patterson C, Soltész G for the EURODIAB Substudy 2 Study Group. Perinatal risk factors for Substudy 2 Study Group. Perinatal risk factors for
childhood type 1 diabetes in Europe. Diabetes Care childhood type 1
1999;22:1698-702.

\section{Other secular trends may explain} associations with diabetes risk

EDITOR-The report by Bingley et al of an association between age of the mother and birth order, and risk of type 1 diabetes mellitus in children is of interest, but the findings do not seem to be consistent. ${ }^{1}$ If the age of the mother is associated with a real increase in risk, then it is surprising that subsequent children could possibly have a reduced risk given that maternal age must have increased. The hypothesis given to explain the apparent relation, of more mature immune responses in older women priming the fetal system in some way, is biologically improbable given the functional immaturity of the fetal immune system.

Since the cohort spans a significant interval, it is not clear that Bingley et al have adjusted for secular trends that might have been associated with greater risk. The most important of these factors is the trend towards childbirth in older women over the study period. The greatest risk of type 1 diabetes mellitus was reported in the offspring of a very small group of mothers giving birth after 45 years of age. ${ }^{1}$

Several other factors in older women might have influenced the reported observation, including assisted reproduction, ethnicity, maternal illness, and obesity that were not presented.

Other potentially confounding factors not examined include the changing incidences of type 1 diabetes mellitus and the increasing rate of obesity in childhood which tends to lower the age of onset of children at risk of type 1 diabetes, because of insulin resistance. $^{23}$

Type 1 pre-diabetes antibodies were apparently not measured to validate the diagnosis of type 1 diabetes mellitus. Clinical diagnosis based on apparent requirement for insulin treatment or presentation with ketoacidosis is not specific at a time of increasing type 2 diabetes mellitus in children.

\section{Alistair J Gunn paediatrician}

aj.gunn@auckland.ac.nz

Wayne S Cutfield paediatrician

Paul L Hofman paediatrician

Craig Jeferries clinical fellow

Department of Paediatrics, University of Auckland, Auckland, New Zealand Bingley PJ, Douek IF, Rogers CA, Gale EAM. Influence of maternal age at delivery and birth order on risk of type 1
diabetes in childhood: prospective population based family study. $B M J$ 2000;321:420-4. (12 August.)

2 Rangasami JJ, Greenwood DC, McSporran B, Smaill PJ, Patterson CC, Waugh NR. Rising incidence of type diabetes mellitus in Scottish children 1984-93. Arch Dis Child 1997;77:210-3.

3 Kitigawa T, Owada M, Urakami T, Tajima N. Epidemiology of type 1 (insulin dependent) and type 2 (non-insulindependent) diabetes mellitus in Japanese children. Diabetes Res Clin Pract 1994;24(suppl):S7-13.

\section{Association may disappear after} adjusting for year of birth

EDITOR-Bingley et al reported an association between increased age of the mother at delivery and increased risk of type 1 diabetes in children. ${ }^{1}$ The simultaneous increase in diabetes and maternal age in the population during the period of recruiting families may have led to a spurious association confounded by unknown factors that have caused the rise in the incidence of diabetes and are simply correlated with increased maternal age in the population over time.

Since siblings are usually born within a few years, the year of birth has been controlled to some extent, but not completely. Adjusting the analyses for year of birth should control such potential confounding. Since Bingley et al did not state that adjustment for birth year was done, the observed association may be at least partly the result of such confounding.

Furthermore, it is possible that genetic susceptibility as indicated by having a sibling with type 1 diabetes increases the relative risk conferred by a high maternal age. If this is the case, the data presented by Bingley et al would not be generalisable to the general population. ${ }^{2}$

The claim that matching for genetic susceptibility is an advantage compared with studies using population controls ${ }^{1}$ applies only if genetic susceptibility is a confounder and not an effect modifier. Genetic susceptibility to type 1 diabetes in the children must be associated with the mother's age at delivery in order to be a confounder in studies using population controls; something that is hard to envisage.

We did a cohort analysis of all live births in Norway between 1984 and 1998, including 1105 children who developed type 1 diabetes, by linking the medical birth registry of Norway with the national childhood diabetes registry. ${ }^{3}$ Our study should have sufficient power to detect even weak associations. We found no significant association between maternal age and the incidence of type 1 diabetes, neither crude nor after adjustment for birth order and year of birth. In Norway, mean maternal age has increased in recent years, but the incidence of diabetes has not. However, the criteria for registration of cases dictate that during any period of registration, those who are born later have a younger age at onset. We observed a crude association between maternal age and age at onset among cases similar to those found by Bingley et al, but the association disappeared after adjusting for year of birth. We suspect that this would be the case for the data of Bingley et al, too.

Lars Christian Stene research fellow

Section of Epidemiology, National Institute of

Public Health, N-0403 Oslo, Norway

lars.christian.stene@folkehelsa.no

Geir Joner paediatrician

Aker Diabetes Research Centre, Aker University Hospital, Oslo, Norway

1 Bingley PJ, Douek IF, Rogers CA, Gale EAM. Influence of maternal age at delivery and birth order on risk of type 1 diabetes in childhood: prospective population based family study. BMJ 2000; 321:420-4. (12 August.)

2 Andrieu N, Goldstein AM. Use of relatives of cases as controls to identify risk factors when an interaction between environmental and genetic factors exists. Int J Epidemiol 1996;25:649-57

3 Irgens LM. The medical birth registry of Norway. Epidemiological research and surveillance throughout 30 years. Acta Obstet Gynecol Scand 2000;79:435-9.

4 EURODIAB ACE Study Group. Variation and trends in incidence of childhood diabetes in Europe. Lancet 2000;355:873-6.

\section{Authors' reply}

EDitor-We accept Byrne's trenchant comments about birth order and retract this conclusion. The effects of maternal age, paternal age, and sex were, however, still present when we reanalysed the data exactly as he suggested. In this reduced sample of 2314 children, Cox proportional hazard regression showed that the risk of type 1 diabetes increased by $12.6 \%$ (95\% confidence interval $6.0 \%$ to $9.6 \%$ ) for each five year band in maternal age at delivery, and by $8.5 \%(3.0 \%$ to $14 \%)$ for each five year increase in paternal age at delivery. As in the published analysis, standard errors have been adjusted for clustering within families.

Readers need not be suspicious about the high risk of diabetes in this cohort since probands were included in the analysis. Potential bias resulting from shorter follow up of later born siblings was minimal since, in contrast to the EURODIAB study, this is a long term prospective family study. The 
median age of randomly selected control siblings in the reanalysis was 16 , while probands were diagnosed at a median age of 10.7 years.

These correspondents question whether our observations can be generalised to the population as a whole, but they may have misunderstood the assumptions underlying this approach. Our study is population based, ${ }^{1}$ and the families therefore represent the subset of children in the region who are genetically susceptible to type 1 diabetes. Relative risks within genetically susceptible families were based on comparison of cases and sibling controls. To relate these to the incidence of diabetes in the region we assumed genetic susceptibility and other factors determining progression to diabetes were independent of maternal age and that the proportion of children with genetic susceptibility remained constant. Simple algebra then shows the incidence of diabetes is proportional to the product of the relative risk for each maternal age group and the proportion of children in that group, thus permitting the potential impact of changes in maternal age distribution to be assessed.

Previous studies using population controls show a similar effect of older maternal age, as do Patterson et al, although the failure to reproduce this in the Norwegian sample is clearly important. We acknowledge the risk of a spurious association when both maternal age at delivery and the incidence of diabetes are rising. We were unable to adjust for date of birth as suggested because this was not a birth cohort study and many of the children were born outside the ascertainment period of 1985-99. The distributions of dates of birth were, however, similar in probands and sibling controls $(P=0.6)$. Misclassification of diabetes was not a problem since $96 \%$ of 491 probands tested had antibodies to glutamate decarboxylase or IA-2, or both. ${ }^{2}$

Future studies will need to take account of the important considerations raised by these correspondents.

Polly J Bingley reader

Edwin A M Gale professor of diabetic medicine Diabetes and Metabolism, Division of Medicine, University of Bristol, Southmead Hospital, Bristol BS10 5NB

1 Gardner SG, Bingley PJ, Sawtell PA, Weeks S, Gale EAM and the BOX Study Group. Rising incidence of insulin-dependent diabetes in children aged under 5 years in the Oxford Region: time trend analysis. $B M$ 1997;315:713-717

2 Bingley PJ, Bonifacio E, Williams AJK, Genovese S, Bottazzo GF, Gale EAM. Prediction of IDDM in the general population: strategies based on combinations of autoantibody markers. Diabetes 1997;46:1701-10.

\section{Human consequences of foot and mouth disease are more than described}

EDITOR-The article by Prempeh et al on the implications of foot and mouth on human health has considered only the disease itself. ${ }^{1}$ Some of your respondents have made reference to mental health effects as a result of the outbreak, but I see no mention of the wider implications for health resulting from the method of controlling the disease. Cumbria seems to have been sitting under a pall of smoke. Have the local hospitals reported an increased intake of respiratory illnesses which coincide with the appearance of "animal bonfires"? Will they monitor for this possibility? The burning of straw and stubble has been illegal for some years, yet this is the very fuel being used to maintain the burning of the carcasses.

There are guidelines for the widespread use of disinfectant to help prevent the spread of the disease; given the quantities involved, what human health implications are there from absorption or inhalation of the products in use? It is likely that there will be an environmental cost to watercourses from the disinfectant as it reaches the waterways from run off. Will there be extra surveillance of human health for the possibility of ill health resulting from contaminated water? Foot and mouth disease may not affect human health, but the way in which we deal with it certainly will.

Gillian Gibson environmental consultant Wirral Health Authority (secondment),

St Catherine's Hospital, Tranmere, Birkenhead CH42 0LQ

Gillian.gibson@exchange.wirral-ha.nwest.nhs.uk

1 Prempeh H, Smith R, Müller B. Foot and mouth disease: the human consequences. BMJ 2001:32:565-6. (10 March.)

\section{Referral guidelines for cancer need closer scrutiny}

EdiToR-The United Kingdom Department of Health's recently published specialty referral guidelines for suspected cancers are likely to add to the confusion of appropriate referrals for primary care physicians. ${ }^{1}$ Under guidelines for urgent referral to a chest physician falls the symptom of stridor. ${ }^{2}$ We think that this should be ignored. All patients with stridor should be referred to ear, nose, and throat physicians so that they can have a nasendoscopy within minutes of their arrival in the emergency ward. The same cannot be said for the availability of bronchoscopy in most hospitals We are concerned that this guideline will increase the occurrence of finding a stridulous patient with laryngeal cancer sitting on a chest ward being treated with nebulisers, awaiting a bronchoscopy.

Equally bemusing is the inclusion of unilateral sensorineural hearing loss as a symptom for urgent referral to a neurosurgeon for exclusion of a brain tumour. Given the incidence of asymmetric sensorineural hearing thresholds in the United Kingdom is $0.7 \%$ (Medical Research Council national study of hearing data) one can estimate some 420000 new cases a year. Most of these patients currently never present and are subsequently never investigated. Even after presentation to a primary care physician the differentiation between sensorineural and conductive hearing loss on the basis of tuning fork tests alone can be very difficult. When such patients are referred to a specialist centre and investi- gated, acoustic neuromata are found to account for only $4-5 \%$ of cases. ${ }^{3}$ The requirement to review such patients within two weeks seems excessive to us given that acoustic neuromata are slow growing and are increasingly being treated conservatively anyway. Lets hope that our neurosurgical colleagues all have an audiologist at their disposal and that their magnetic resonance imaging scanner is able to run 24 hours a day to cope with the extra demand.

Assuming the management of unilateral hearing loss remained within the remit of the ear, nose, and throat department, we reviewed our general practice referrals to a unit with two consultants over one month. By strictly applying the new guidelines 51\% of referrals fell into the urgent category. Only $12 \%$ of the referrals warranted an urgent appointment. Although we applaud any attempt to improve survival rates for head and neck malignancy we worry that poorly devised guidelines can soon result in a gridlocked clinic, not to mention confused general practitioners who are unsure to which specialty they should be referring.

Jeffrey $\mathbf{L}$ Lancaster specialist registrar in otolaryngology, head and neck surgery jeffreylancaster@hotmail.com

I W Sherman consultant otolaryngologist, head and neck surgeon

Arrowe Park Hospital, Merseyside CH49 5PE

Competing interests: none declared.

1 Mayor S. English government sets out first national cance standards. BMJ 2001;322:192. (27 January.)

2 Referral guidelines for suspected cancer. Available at: www.doh.gov.uk/pub/docs/doh/guidelines.pdf

3 Swan IRC, Gatehouse S. Clinical and financial audit of diagnostic for protocols for lesions of the cerebellopontine angle. BMJ 1991;302:701-4.

\section{Assessment of grouping variable should have been blind in trial of dementia}

EDITOR-Huusko et al studied the effect of intensive geriatric rehabilitation on dementia patients with hip fracture. ${ }^{1}$ The reported study was probably the first randomised study with predetermined subgroup analysis according to the degree of dementia in this growing patient group. The degree of dementia was classified by the score on the minimental state examination. ${ }^{2}$ The median length of hospital stay of patients with hip fracture who had moderate dementia was 47 days in the intervention group and 147 days in the control group $(\mathrm{P}=0.04)$. The corresponding values for patients with mild dementia were 29 days in the intervention group and 46.5 days in the control group $(\mathrm{P}=0.002)$.

Huusko et al concluded that patients with hip fracture and mild or moderate dementia can often return to the community if they are provided with active geriatric rehabilitation. Pioneering work is never easy. Even though the study seemed to be well conducted, the patients in the intervention group were stated to have a highly significant deeper level of dementia compared with the control group $(\mathrm{P}<0.001)$. 
This was considered as coincidental, even though such a difference in outcome would be considered to be definitive proof of treatment effect in any medical trial. The degree of dementia was used as grouping variable when testing the effect of intervention on the outcome and thus probably had a fundamental effect on the obtained results.

The problem is that the degree of dementia was stated about one week after admission to the geriatric ward of the central hospital or the local hospital, 10 days after surgery and randomisation. The person scoring the minimental examination knew the treatment group, and this person was probably different in the control and in the intervention group. This may have caused biased classification of dementia and may explain the observed difference in minimental state examination between the study groups. ${ }^{3}$ Thereafter, recovery of patients in the intervention group without true dementia may have been compared with patients in the control group with mild dementia, and so on, which might explain an appreciable part of the observed results in the study.

Conducting this sort of randomised study is very demanding, but it is recommended to try to blind assessment of the main grouping factor.

Petri E Voutilainen trialist

Department of Cardiothoracic Surgery, FIN-33251 Tampere, Finland

petri.voutilainen@tays.fi

1 Huusko TM, Karppi P, Avikainen V, Kautiainen H, Sulkava R. Randomised, clinically controlled trial of intensive geriatric rehabilitation in patients with hip fracture: subgroup analysis of patients with dementia. BMJ 2000;321:1107-11. analysis of pati

2 Folstein MF, Folstein SE, McHugh PR. "Mini-mental state". A practical method for grading the cognitive state of
A A practical method for grading the cognitive state of
patients for the clinician. J Psychiatric Res 1975;12:189-98. 3 patients for the clinician.J Psychiatric Res 1975;12:189-98. 3 Schulz KF. Subverting ran
JAMA 1995;274:1456-8.

\section{Portal hypertension}

\section{Where is evidence for $5 \%$ dextrose and pulmonary artery catheter?}

EDITOR-In their clinical review of portal hypertension Krige and Beckingham have given recommendations for treatment. ${ }^{1}$ They claim that variceal bleeding due to portal hypertension should initially be treated with rapid infusions of $5 \%$ dextrose and colloid solution, and they advise against saline infusion as it may aggravate ascites. Furthermore, they recommend using a pulmonary artery catheter for monitoring patients who are haemodynamically unstable, are elderly, or have concomitant cardiac or pulmonary disease.

The authors have not provided any scientific evidence for these recommendations. I am not aware of any randomised controlled study that has compared the combination of $5 \%$ dextrose and colloid infusion with saline infusion in patients with ascites and variceal bleeding. Similarly, the advice to use a pulmonary artery catheter is questionable and not based on scientific evidence. A prospective cohort study with 5735 critically ill adult patients showed this procedure to be harmful. ${ }^{2}$ The results of a multicentre study from the United Kingdom are still awaited.

Joseph Osterwalder head of emergency department Kantonsspital, CH-9007 St Gallen, Switzerland znala@ms1.kssg.ch

1 Krige JEJ, Beckingham IJ. ABC of diseases of live pancreas, and biliary system. Portal hypertension-1: varices. BMJ 2001;322:348-51. (10 February.)

2 Connors AF Jr, Speroff T, Dawson NV, Thomas C, Harrell FE Jr, Wagner D, et al. The effectiveness of right heart catheterization in the initial care of critically ill patients. SUPPORT Investigators. JAMA 1996:276:889-97.

3 Derek A, Black N. Wider lessons of the pulmonary artery catheter trial. BMJ 2001;322:446. (24 February.)

\section{Authors' reply}

EDITOR-ABC series do not include detailed discussion, and, as with so many areas of medicine and surgery, there are few randomised controlled data on portal hypertension on which to draw. We are, however, surprised at the points that Osterwalder raises.

It is well established and common practice that patients with cirrhosis and liver failure should not be given saline, which may aggravate their hypernatraemia. Colloids and $5 \%$ dextrose are therefore the preferred fluids for resuscitation fluid. ${ }^{12}$

There is an increasing awareness of the complications associated with monitoring pulmonary artery wedge pressure, which were clearly shown in the study quoted by Osterwalder. It is difficult to draw analogies from these data as the patients in this homogeneous study group did not have liver failure and variceal bleeding and were not randomised.

We stand by our views that in the group of patients stated (elderly patients, with concomitant cardiac or pulmonary disease who are haemodynamically unstable from a variceal bleed) it is extremely important to monitor fluid resuscitation closely. The virtues of monitoring pulmonary wedge pressure in these patients are widely recognised, and this practice is recommended by many authors. ${ }^{34}$ Until such time as a randomised trial fails to show benefit, this must therefore remain the gold standard treatment in severely ill patients with these criteria.

J E J Krige associate professor of surgery Groote Schuur Hospital, Cape Town, South Africa

I J Beckingham consultant hepatobiliary and laparoscopic surgeon

Department of Surgery, Queen's Medical Centre, Nottingham NG7 2UH

Ian.Beckingham@nottingham.ac.uk

1 Strunin L. Anaesthetic management of patients with live disease. In: Miller-Sadler G, Wright R, Arthur MJP, ed Wright's liver and biliary disease. London: Saunders, 1999.

2 Riordan SM, Williams R. Management of liver failure. In Blumgart, Fong, eds. Surgery of the liver and biliary tract. London: Saunders, 2000.

Williams R. Acute hepatic failure. In: Oxford textbook of critical care. Oxford: Oxford University Pres.

4 MacMathuna P, Westaby D, Williams R. Portal hypertension; pathophysiology diagnosis and treatment In: Miller-Sadler G, Wright R, Arthur MIP, eds. Wright's liver

\section{Back to tale of seven surgeons}

EDIToR-I was able to identify the doctors mentioned in Prior's personal view from the clinical notes.

Surgeon one was a specialist registrar who was working in my department several years ago, who investigated the initial problem of submandibular gland swelling.

The second consultation, some years later after discharge and referral, was with me, and I suggested surgery to remove the gland. It is my habit to explain the complications of surgery in more detail than is reported, but the patient's memory is more important than my own in this context.

Surgeons three and four were specialist registrars working in my department. Surgeon five was the on call senior house officer from the other hospital on our rotation as this event occurred at $10 \mathrm{pm}$. Surgeon six was almost certainly surgeon four, but wearing civilian clothes rather than a theatre outfit. He was doing the ward round with the rest of the junior team, which should have consisted of surgeons three, four, and seven. Surgeon seven was the senior house officer reviewing the patient one week after the operation to check the wound and give the pathology report.

The criticisms in the article are constructive, and the patient did manage to see all the members of the team individually, which is unusual but certainly not impossible. I am concerned that the individual doctors did not introduce themselves adequately and that Prior did not feel that she could get in touch with us to express her concerns about the residual nerve weakness. Both these issues have been addressed, and I hope that our performance will be better in future.

The case does, however, highlight a problem with the present health service. We hope that it will become a consultant led service, but one person can do only so much surgery in one year. The public may not realise that experienced junior staff often do operations to use available theatre time during colleagues' holidays. Training programmes involve trainees at all levels, so patients often see several doctors. The final responsibility for patients' care rests with the consultant, but this is not always clear to the patient

The personal view has been discussed in our department, and I hope that it will improve our performance.

1 Prior P. A tale of seven surgeons. BMJ 2001;322:1433. (9 June.)

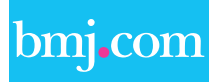

\section{Rapid responses}

Correspondence submitted electronically

is available on our website 